\title{
DICIONÁRIO ON LINE SPREAD THE SIGN digital para a educação: Integração internacional de um recurso para surdos
}

Recebido em 21.12.2013. Aprovado em 28.12. 2013 Avaliado pelo sistema double blind review

\author{
Renata Rodrigues de Azevedo \\ azevedo.renata@yahoo.com.br \\ Instituto de Educação Professor Ismael Coutinho - Niterói -RJ - Brasil.
}

\section{Resumo}

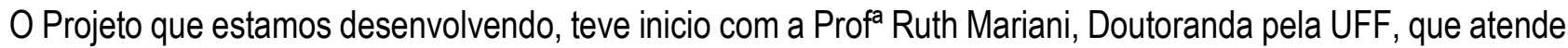
aproximadamente 40 alunos surdos na sala de recurso. Percebemos sempre que após os Conselhos de Classes, a maioria dos alunos surdos apresentava baixo rendimento, com dificuldades em compreender conceitos das disciplinas. Sabemos que alguns erros na interpretação de uma aula podem prejudicar 0 processo de aprendizagem do aluno surdo.

A comunicação é imprescindivel para todos, inclusive para os alunos surdos, para que estes tenham, através de uma melhor relação, condições de não exercerem seu trabalho isolada e mecanicamente, como sempre Ihes foi exigido e feito, mas que saibam e sintam sua real inserção no ambiente escolar, o que é fundamental para seu desenvolvimento profissional e pessoal. Assim a implantação do Dicionário on line Spread the sign, pioneiro no Brasil, poderá ampliar a comunicação e o acesso destas pessoas com deficiências.

Tentamos nos adequar as dificuldades que são apresentadas, pois promover a inclusão significa uma mudança de postura, implica em quebra de paradigmas, em reformulação do nosso sistema de ensino para a conquista de uma educação de qualidade e prevendo a permanência de todos os alunos na escola independentemente de suas diferenças e necessidades.

Nesta perspectiva, baseada no reconhecimento da diversidade humana, a educação se reestrutura, revendo currículos e políticas educacionais, para cumprir com o papel de formação da cidadania competente, participativa na vida social, resguardada em sua singularidade, e na forma de repúdio a toda manifestação de discriminação.

Para a realização deste empreendimento, o valor solicitado ao edital será de $\mathrm{R} \$ 31.394,20$, destinados à compra de alguns equipamentos.

Estamos convencidos de que este Projeto criará um novo olhar na perspectiva de aprendizagem dos surdos, mas não apenas técnico, e sim na construção humanística da sociedade, este empreendimento vem ao encontro do Programa de Melhoria da Aprendizagem nas Escolas, da Fundação Novo Brasil - Educação para o Futuro, do qual esperamos 0 apoio financeiro para o êxito do projeto que apresentaremos mais minuciosamente nos próximos capítulos.

Palavras-chaves: Educação. Tecnologias de ensino. Plano de empreendimento. Inclusão. 


\section{DICIONÁRIO ON LINE SPREAD THE SIGN digital para a educação: Integração internacional de um recurso para surdos}

\section{Contexto da escola}

O Instituto de Educação Professor Ismael Coutinho foi fundado em 1835 e fica localizado na cidade de Niterói/ RJ. São 1200 alunos atendidos nas modalidades: Ensino Fundamental I ( $4^{\circ}$ e $5^{\circ}$ ano), Ensino Fundamental II, Ensino Médio (Curso Normal), EJA Fundamental (do $1^{\circ}$ ao $5^{\circ}$ ano) e Programa Autonomia Fundamental e Médio.
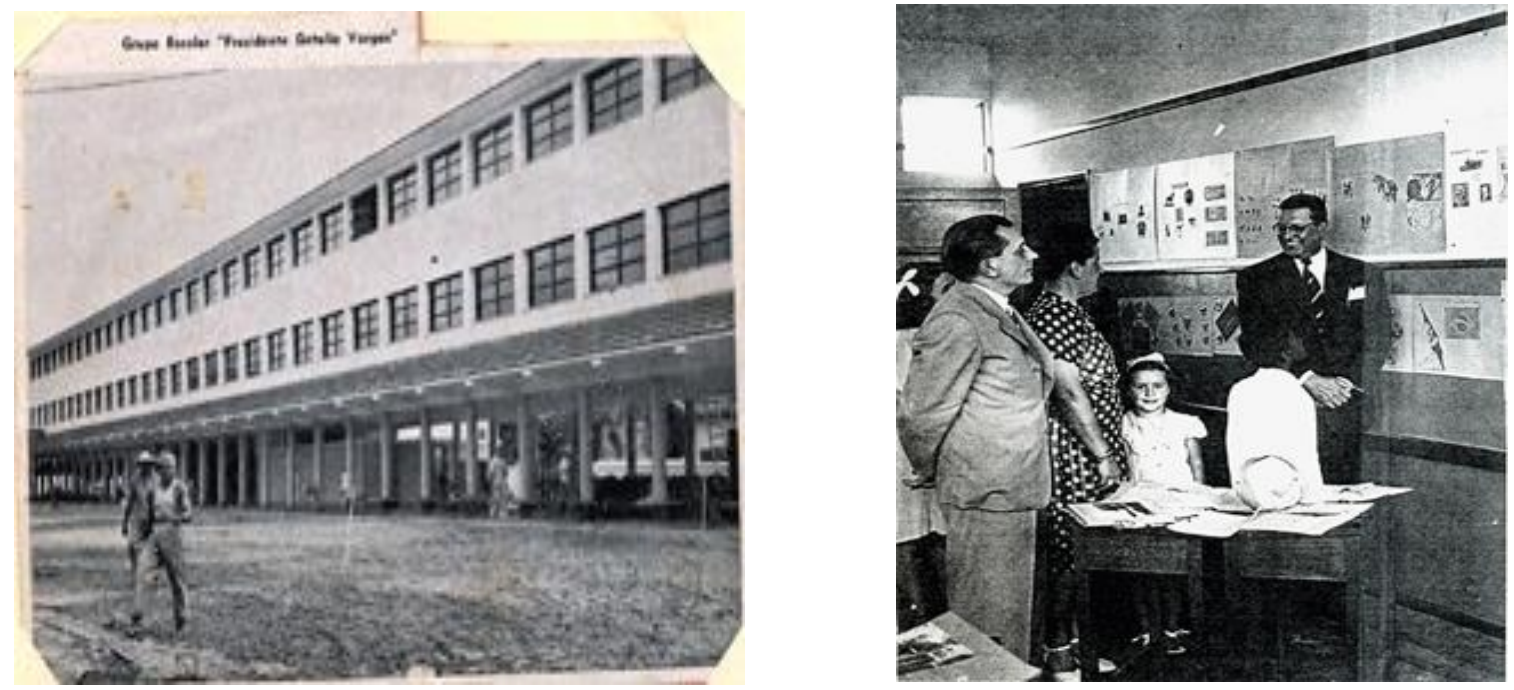

Figura 1: Professor Ismael Coutinho (terno preto) visitando o Instituto de Educação.

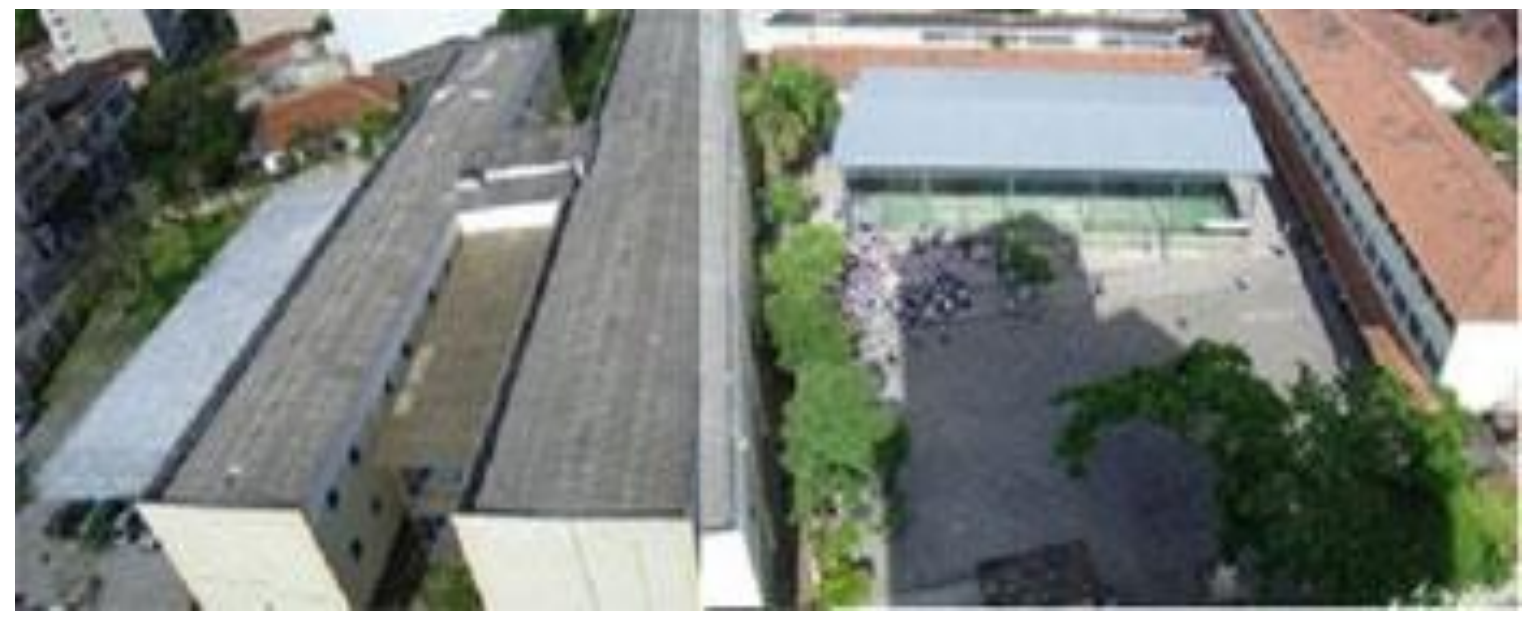

Foto: Panorâmica da escola.

Missão: Buscar uma educação inclusiva e coletiva, preparando os nossos alunos para a vida contemporânea com qualidade, tendo no Curso Normal, uma educação humanista.

Visão: Ser reconhecida como uma escola de qualidade e de referência na Formação de Profissionais de Educação e na educação inclusiva. 
Valores: Nossa filosofia de educação procura valorizar a participação do aluno na construção do conhecimento. Busca a implementação de uma prática pedagógica que leve 0 aluno a pensar, observar, pesquisar, julgar e concluir. Propiciar uma educação inclusiva, pautada na solidariedade, no acolhimento e na promoção da auto-estima.

\section{Breve Histórico}

O Instituto de Educação Professor Ismael Coutinho (IEPIC), é a primeira instituição dedicada à formação de professores da América Latina, segue a produzir suspiros por toda a parte, sobretudo entre estudantes e docentes que ali reeditam suas biografias. Fundado em $1^{\circ}$ de abril de 1835 , a história do Instituto se confunde com a do Brasil Império (1822 - 1889) e com a própria trajetória pedagógica brasileira. Depois de ser extinta em 1851, a mais antiga Escola Normal do país foi reinaugurada pelo imperador Dom Pedro Il no dia 29 de junho de 1862 e, desde então, tornou-se referência em educação e passou a oferecer os níveis Básico, Fundamental e Médio, além da Educação de Jovens e Adultos (EJA).

Desde sua origem em 01/04/1835, o Instituto teve sede em alguns lugares na cidade e por fim seu desligamento do Liceu Nilo Peçanha pela Lei n 2146, em 1954, o Instituto de Educação do Estado do Rio de Janeiro passou a denominar-se INSTITUTO DE EDUCAÇÃO DE NITERÓI, sendo transferido para a Travessa Manoel Continentino, Ingá.

Hoje, a inclusão de jovens com necessidades especiais e o respeito à diversidade são as grandes vocações que orientam o Instituto, num pioneirismo que ficou consagrado com a criação da Sala de Recursos Multifuncional, que disponibiliza materiais para atender a diversas formas de deficiência. São cerca de 1.200 alunos e 150 professores, empenhados em perpetuar não só a tradição da escola e o seu discurso pela cidadania, mas em agir sob a defesa de um ensino diferenciado, formador de educadores e, antes de tudo, de seres humanos.

\section{Professores}

Nosso corpo docente apresenta um grande comprometimento com a qualidade da educação e estão em constantes capacitações e discussões sobre políticas educacionais, $60 \%$ dos nossos professores possuem Pós Graduação, 30\% Mestrado e 10\% Doutorado. A equipe gestora da escola é composta por um Diretor Geral e dois Diretores Adjuntos, dois Coordenadores Pedagógicos, 1 Professor Orientador Educacional. A escola promove em parceria com a Universidade Federal Fluminense formação continuada na educação inclusiva para professores e formandos do curso normal.

\section{Alunos}

A escola possui 47 turmas, dividida em 3 turnos. Atendemos 1200 alunos, sendo que 234 do Curso Normal , em horário integral, o que totaliza 1450 alunos.

\begin{tabular}{|l|l|}
\hline MODALIDADES DE ATENDIMENTO & QUANTIDADES DE ALUNOS \\
\hline ENS. FUNDAMENTAL I & 175 \\
\hline ENS. FUNDAMENTAL II AUTONOMIA & 100 \\
\hline $\begin{array}{l}\text { PROGRAMA FUNDAMENTAL } \\
\text { PROGRAMA AUTONOMIA MÉDIO }\end{array}$ & 40 \\
\hline CURSO NORMAL & 468 \\
\hline EJA FUNDAMENTAL II IALTAS & 87 \\
\hline $\begin{array}{l}\text { ALUNOS ESPECIAIS } \\
\text { HABILIDADES }\end{array}$ & 130 \\
\hline
\end{tabular}




\section{DICIONÁRIO ON LINE SPREAD THE SIGN digital para a educação: Integração internacional de um recurso para surdos}

Na educação inclusiva, atendemos 50 alunos surdos, 1 aluno cego, 2 alunos com baixa visão, 1 cadeirante, 5 com TGD/Autismo, além de 40 alunos com Altas Habilidades, que possuem atendimento especializado na Sala de Recursos Multifuncional, no contra turno. A Sala de Recursos do Instituto de Educação Professor Ismael Coutinho tem como propósito ser complementação e suplementação curricular, onde estes são abertos e flexíveis que passam a ser condição fundamental para organizar as respostas educativas compatíveis com as necessidades dos alunos.

\section{Características mais marcantes do local onde a escola se insere}

A escola localiza-se no bairro do Ingá, em Niterói, e apesar da sua localização ser em uma área nobre, e de muitos espaços históricos, nossa clientela do Ens. Fund. I (em terminalidade), Ens. Fund. II e EJA, basicamente são das Comunidades do entorno (Morro do Estado, Morro do Palácio e Morro do 94), que vivem em constantes conflitos de violência. Difere-se 0 atendimento para o Curso Normal, onde nossos alunos são oriundos dos mais diversos municípios da cidade do Rio de Janeiro, devido a sua tradição no ensino profissionalizante na Formação de Professores.

Temos como ponto forte as parcerias com APADA e as Universidades ao entorno (UFF e FAMATH), onde atendemos mensalmente uma média de 150 estagiários de diversas disciplinas, e consolidamos parceria com a UFF em projetos como: PIBID (através da Profa Maura e demais professores coordenadores da UFF e do IEPIC) e Escola de Inclusão ( com Profa Cristina Delou e equipe).

Devido à localização e pelo seu espaço físico, a escola é muito utilizada pela comunidade e possui parcerias esportivas com várias instituições local.

\section{Identificação do problema ou da oportunidade}

A educação no Brasil atualmente tem um grande desafio na garantia da inclusão de todos os alunos no sistema regular de ensino. Segundo a Constituição Federal de 1988, Capítulo III, Seção I, Artigo 205, a educação é um direito de todos e dever do Estado e da família, que deverá ser promovida e incentivada com a colaboração da sociedade, visando ao pleno desenvolvimento da pessoa, seu preparo para o exercício da cidadania e sua qualificação para o trabalho (Brasil, 1988). Entretanto, mesmo tendo garantido por lei o direito à educação, uma expressiva parcela da população encontra-se fora da escola, sendo esta questão mais grave quando se considera os alunos com necessidades especiais (Santos,2009).

A comunidade surda brasileira tem como base de sua educação a Língua Brasileira de Sinais (Libras), oficializada em abril de 2002 (Lei n. 10.436, de 24 de abril de 2002). Em Portugal, o decreto 3/2008 de 7 de Janeiro objetivou uma mudança no ensino da comunidade surda favorecendo ao ensino Bilíngüe.

A comunicação humana é um processo que envolve a troca de informações e utiliza os sistemas simbólicos para o desenvolvimento do pensamento e da linguagem. Por isto este projeto tem como objetivo criar a possibilidade dos surdos do Brasil se comunicar com a comunidade surda do Mundo, através da Implantação do projeto Spread the Sign no Instituto de Educação Professor Ismael Coutinho.

\section{Apresentação e análise dos resultados}

Pesquisadores mostram que estudantes surdos têm sido descritos como pessoas de baixo rendimento escolar, contudo este estigma que os acompanhou pela sua história tem comprometido a sua aprendizagem (Marinho, 2007, Santana 2010). Os números do senso escolar confirmam estes dados: dos 56.000 surdos que chegam para o ensino fundamental somente 300 estão nas Universidades Brasileiras. Aparentemente, os surdos não estão conseguindo expressar os conhecimentos nas diferentes áreas, mesmo quando utilizado uma pré- 
abordagem, sendo a compreensão totalmente comprometida quando o conteúdo se apresenta na forma de texto, mesmo que coloquial (Rumjanek, 2008; Marinho, 2007). A ausência dos termos científicos, neste contexto, parece se apresentar como um fator importante que pode comprometer a compreensão/ apropriação destes conhecimentos pelos alunos (Rumjanek, 2008; Marinho, 2007, Santana 2010). A presença dos intérpretes de Libras nas salas de aulas, assegurado por lei (decreto do Governo Federal ñ . 5.626 de 22 de dezembro de 2005) pretende garantir que os estudantes com deficiência auditiva; matriculados em escolas inclusivas tenham acesso e compreendam o conteúdo ministrado pelo professor. Entretanto, os intérpretes de libras não detêm o conhecimento técnico, ou seja, graduação na área; podendo durante a tradução haver um grande "ruído" de comunicação, dificultando o aprendizado do discente surdo.

\section{Conquista/SEEDUC}

Sabemos da necessidade de capacitação constante dos nossos professores para este atendimento. Conseguimos Apoio Pedagógico para uma aluna autistas, diminuição no quantitativo de alunos surdos no mesmo ano de escolaridade com os ouvintes, (chegamos a atender de 7/8/9 alunos surdos, na mesma turma, além de 30 ouvintes) , os alunos surdos, apresentam diferentes níveis lingüísticos, necessitando de turma menor para um trabalho de qualidade dos professores, que também estão em constante aprendizagem. A Seeduc, está priorizando os intérpretes no atendimento aos surdos, e para 2013 ficou combinado de mantermos no máximo 5 alunos surdos numa turma de 25 alunos, porém o AEE, fundamental atendimento para os alunos especiais, nos preocupa, uma vez que não estamos tendo profissionais especializados na língua de sinais para proporcionar este atendimento, temos poucos profissionais na área.

\section{Oportunidade}

Pensando nos problemas mencionados, trago o tema "DICIONÁRIO ON LINE" Spread the Sign, administrado pela Suécia, abordado por mim neste PLEM. Venho apresentando durante todo Curso de MBA, temas referentes ao Curso Normal, PIBID e Educação Inclusiva. Estamos investindo com novas possibilidades tecnológicas para oferecermos serviço de utilidade, e mecanismo facilitador na escola e no mundo na comunicação das línguas de sinais (No Brasil a Libras + Visualização + escrita) para surdos e ouvintes. Diante da grande demanda de atendimento de alunos surdos na escola e por termos na grade curricular do Curso normal a disciplina de laboratório de Libras, achamos necessário investir no trabalho de inclusão. Nosso propósito é que nossa escola possa consolidar-se como referência na produção de materiais para atendimento aos surdos.

\section{Caracterização do produto/serviço elou processo Público Beneficiado}

No Instituto de Educação Professor Ismael Coutinho, observamos que é fato a distorção idade - série do ensino fundamental e médio dentre os alunos que participam da pesquisa. Dos 42 alunos, 7 são do ensino médio e 35 do ensino fundamental. Destes 42 alunos, 34 são surdos profundos bilaterais, 02 são surdos moderados bilaterais e 07 tem variação entre 0 ouvido direito e esquerdo sendo que um deles é profundo e o outro é moderado. Estes dados são importantes para a pesquisa porque poderá interferir na compreensão do Português como segunda língua. $O$ nível de Interlíngua dos alunos também tem variação apesar de estarem na mesma série, não quer dizer que tenham a mesma compreensão do Português. Temos ainda como componentes beneficiados os familiares, amigos ouvintes, professores e interpretes. 


\section{DICIONÁRIO ON LINE SPREAD THE SIGN digital para a educação: Integração internacional de um recurso para surdos}

\section{Projeto Dicionário on line Spread the sing}

A inclusão não é um tema novo na sociedade onde encontramos ainda os excluídos, os que possuem seus direitos assegurados pela CF, mas que por algum motivo, permaneceu a margem de informações sobre um determinado assunto. Hoje, o IEPIC está envolvido com o DICIONÁRIO ON LINE e, segundo Marinho (2007) os alunos recorrem a dicionários gestuais/de sinais para compreensão, mas estes não atendem suas expectativas por conterem um vocabulário muito básico (ex: fruta, animais, transporte), ou seja um significado geralmente é usado para todos os tipos de aves, o aluno não conhece sinais de outras aves, todas possuem o mesmo sinal, apesar de saberem que são diferentes.

$O$ ensino utilizando o ambiente virtual tem-se revelado uma ferramenta de aprendizagem muito significativa, na medida em que os alunos possam ter a possibilidade de pesquisar o que realmente the interessa. Contudo a sua valorização pedagógica no campo da educação de surdos depende da participação criativa dos docentes (requer ainda incentivos do governo para capacitar professores e elevar o quantitativo de intérpretes) para elaborar situações didáticas que promovam as competências e as aprendizagens dos alunos.

\section{Os dicionários/significados}

As funções principais de um dicionário são: definir os verbetes que não conhecemos; auxiliar o estudo de uma língua e contribuir para uniformizar e manter a unidade da língua. Como a Língua de Sinais tem seus regionalismos para alguns verbetes e para outras palavras cientificas não tem um sinal especifico e necessitando assim o uso da datilologia.

\section{Inovação}

Nosso projeto chama-se: PROJETO INTERNACIONAL SPREAD THE SING, tal dicionário é considerado pela comissão européia exemplo de boas práticas. O Spread The Sing, é um dicionário gestual multilíngüe, gratuito de consulta on line. A sua condição coloca os países participantes a necessidade e responsabilidade de pesquisar gestos/sinais correspondente a cada uma das palavras que vão sendo elaborada nas listas temáticas, para que os mesmos possam ser registrados em vídeos e colocados no site através de uploads.

Nossos alunos surdos, ouvinte e professores estão participando do processo de filmagem. 0 material padrão (fundo de parede laranja e camisa preta) foi entregue pela ONG da Suécia, responsável pelo site, quando esteve presente, no mês passado a Profa ${ }^{\mathrm{RUTH}}$, para conhecer e receber o material. A Bandeira do Brasil já está no site, porém a finalização das filmagens está prevista para final de outubro, são 14 mil palavras, contamos com a participação do INES (como revisor dos sinais), UFF, UFRJ, e CAPES que realizou 0 financiamento do Doutorado /Sanduíche da Profa Ruth Mariani em Portugal e a SEEDUC que autorizou a liberação da doutoranda para sua tese.

No dicionário on line o aluno poderá acessar o idioma que ele quiser e solicitar palavras, que aparecerá a interpretação em libras e acima virá a escrita nos idiomas, ele poderá perceber quais diferenças e semelhanças nas línguas de sinais no mundo. Facilitará diretamente a disciplina de língua estrangeira, já que é difícil para 0 intérprete tentar conceituar ou elaborar sinais e como forma de capacitação para intérprete, professores, familiares dos surdos e pessoas que acreditam na inclusão. Vamos divulgar amplamente este Projeto, será um avanço para o Brasil no atendimento de milhares de surdos. Lembramos que todo o processo do Dicionário on line foi totalmente gratuito e todos os alunos e responsáveis assinaram autorização do uso de imagem. Os gastos serão com despesas pré- operacionais e gastos operacionais, detalhados no decorrer do projeto.

\section{Ações bem sucedidas}


Mesmo com atendimento na sala de recursos, temos limitações de materiais didáticos acessíveis na primeira língua dos surdos, então começamos a desenvolver práticas com vídeo aula de temas de física, biologia, química, com ajuda dos alunos da UFF, onde os alunos surdos são os protagonistas, entendendo assim os conceitos do conteúdo. No trabalho na sala de recursos também foram criados jogos, que estes foram patenteados pelos alunos estagiários da UFF, como o jogo das aves e o caça ao tesouro da tabela periódica. O que comprova que os ganhos da adaptação dos materiais beneficiaram todos... alunos, estagiários e escola, além da elaboração e produção do curta "IEPIC- UMA HISTÓRIA DE INCLUSÃO".

http://saladerecursosiepic.blogspot.com.br/2010_10_01_archive.html

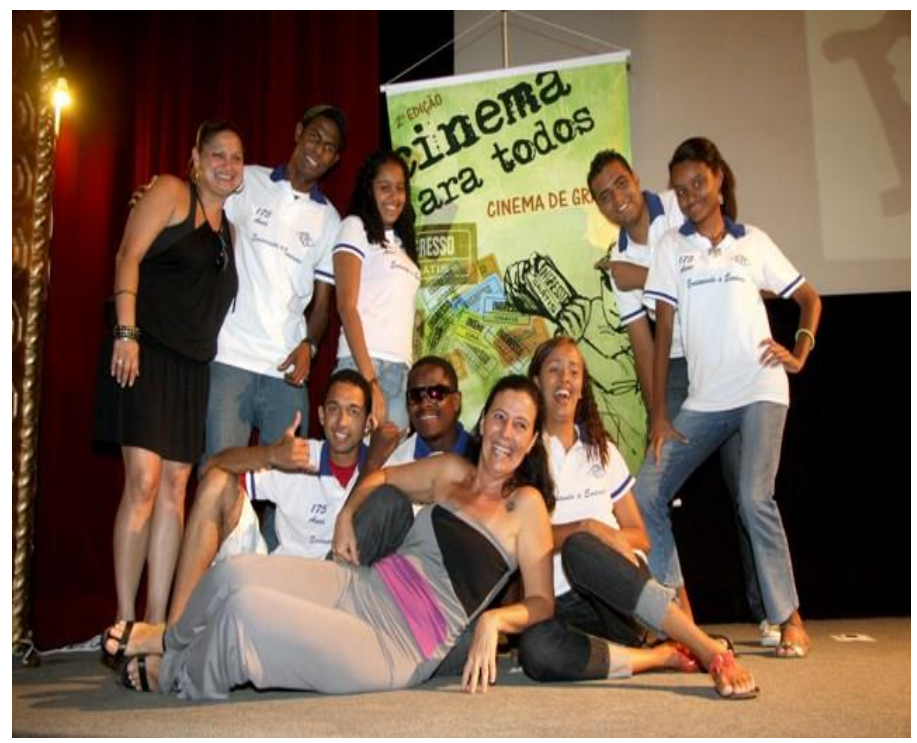

Foto: Premiação $1^{0}$ Lugar- Cinema para Todos

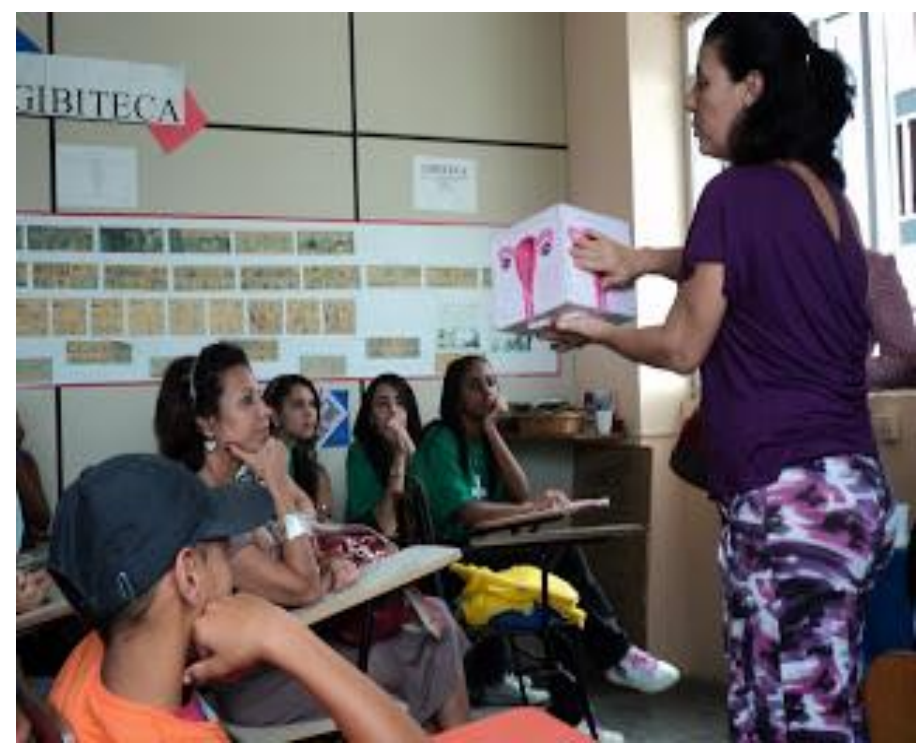

Fotos: Projeto sexualidade para os surdos

\section{Continuidade do Projeto}

Neste momento fazem parte 17 países, representado 17 línguas vocais e 17 línguas gestuais/sinais, o Brasil agora se faz presente com a nossa escola, IEPIC, através da pesquisa da Profa ${ }^{\mathrm{R} U T H}$ MARIANI. Existem cerca de 73.000 vocábulos e o site sobre este projeto é consultado por 2 milhões de pessoas mensalmente. Todo este trabalho coloca, a cada um dos países participantes, a necessidade e a responsabilidade de pesquisar os 


\section{DICIONÁRIO ON LINE SPREAD THE SIGN digital para a educação: Integração internacional de um recurso para surdos}

gestos/sinais correspondentes a cada uma das palavras constantes das listas temáticas que vão sendo construídas.

\section{Estratégia de implementação}

\section{Análise SWOT}

\section{Oportunidades}

- Parceria com Universidades no entorno UFF;

- Encontro Nacional, na escola, sobre a criação de novos verbetes para serem implantados no dicionário;

- Projeto inovador no Brasil, exemplo de boas práticas em outros países;

- Acesso livre e gratuito por todas à plataforma do dicionário;

\section{Forças}

- Significativa demanda de matrículas dos alunos com necessidades especiais;

- Alto grau de qualificação profissional do corpo docente;

- Participação de todos os discentes surdos da escola;

- Apoio dos responsáveis e docentes da escola;

\section{Ameaças}

- A falta de acesso a internet nas residências e escolas;

- A pouca utilização pelos docentes como mecanismo facilitador de aprendizagem;

\section{Fraquezas}

- Necessidade de se ter um computador com grande memória para edição e armazenamento dos vídeos;

- Há falta de capacitação dos interpretes sobre os diferentes temas do dicionário;

\section{Objetivos estratégicos}

\section{Definição das estratégias}

\begin{tabular}{|c|c|c|}
\hline Objetivos & Metas & Estratégias \\
\hline $\begin{array}{l}\text { Possibilitar a implementação de } \\
\text { uma ferramenta multimídia na } \\
\text { forma de um dicionário on line } \\
\text { científico gratuito e aberto, } \\
\text { contendo termos essenciais para o } \\
\text { ensino das diferentes áreas na } \\
\text { Língua Brasileira de Sinais } \\
\text { (Libras). }\end{array}$ & $\begin{array}{l}\text { Assegurar aos surdos condições } \\
\text { de paridade e acessibilidade } \\
\text { educacional, através das } \\
\text { tecnologias computacionais e } \\
\text { recursos digitais, elevando o } \\
\text { índice de aprovação até o fim do } \\
\text { ano de } 2014 \text {. }\end{array}$ & $\begin{array}{l}\text { Utilizar como recursos visuais o } \\
\text { dicionário spread the sing como } \\
\text { ferramenta pedagógica, facilitador na } \\
\text { aprendizagem de novos verbetes e } \\
\text { conhecimento de línguas } \\
\text { estrangeiras. }\end{array}$ \\
\hline
\end{tabular}




\begin{tabular}{|c|c|c|}
\hline $\begin{array}{l}\text { Contribuir para } 0 \text { ensino e } \\
\text { aprendizagem e subsidiar } \\
\text { discussões nas comunidades } \\
\text { surdas e científicas sobre a } \\
\text { questão de ausência de sinais. }\end{array}$ & 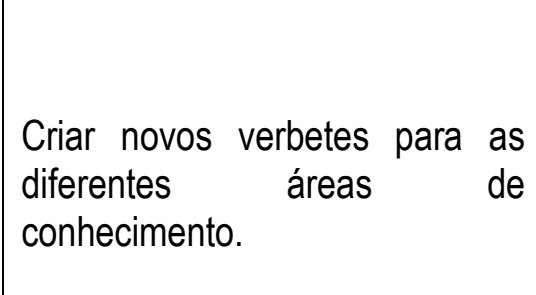 & $\begin{array}{l}\text { Aulas passeios, com diferentes temas } \\
\text { para estimular a curiosidade sobre um } \\
\text { determinado tema para que os surdos } \\
\text { possam entender o conceito e criar o } \\
\text { sinal, este então passa fazer parte do } \\
\text { dicionário. }\end{array}$ \\
\hline
\end{tabular}

\section{Plano de Ação}

\section{Estratégico}

Por que?

A partir dos baixos rendimentos dos alunos surdos con dificuldades em compreender conceitos nas disciplinas.

\section{Quanto?}

Aproximadamente $\mathrm{R} \$ 31.394,20$ Dividida em despesas pré- operacionais e gastos operacionais

\section{Gerencial}

\section{0 que?}

Dicionário on line Spreadt Thes Sing , onde o aluno surdo e ouvinte poderá acessar palavras de vários países, que aparecerá em libras, facilitando sua aprendizagem, principalmente em línguas estrangeiras.

\section{Operacional}

\begin{tabular}{|l|l|l|}
\hline \multicolumn{1}{|c|}{ Quem? } & \multicolumn{1}{|c|}{ Quando? } & \multicolumn{1}{c|}{ Onde? } \\
\hline $\begin{array}{l}\text { Instituto de Educação Professor Ismael } \\
\text { Coutinho }\end{array}$ & $\begin{array}{c}\text { Previsão de término } \\
\text { Novembro de 2013 }\end{array}$ & $\begin{array}{l}\text { Site: } \\
\text { www.spreadtThesSing.com }\end{array}$ \\
Profa: Ruth Mariani/Sala de Recursos & & \\
& & \\
\hline
\end{tabular}

\section{Como?}

Produção de um banco de dados de imagens sobre palavras existentes.

Filmagens do vocabulário do cotidiano e a tradução dos verbetes em Inglês para o Português, utilizando metodologias de computação gráfica, envolvendo: níveis de acesso de memória, movimentação gráfica, complexidade e interatividade.

Termos de responsabilidade de participação na pesquisa, autorização de uso de imagens e as perguntas do questionário, em Língua Gestual Portuguesa registrando através de uma máquina de filmar suas respostas.

Croma Key, material padrão (fundo de parede laranja e camisa preta), para realização da filmagem. 


\section{DICIONÁRIO ON LINE SPREAD THE SIGN digital para a educação: Integração internacional de um recurso para surdos}

\section{Indicadores de Analise}

Os indicadores do projeto são os dados estatísticos dos verbetes postados na plataforma WWW.spreadthesign.com, bem como a aplicação dos questionários que participarão no mínimo 10 alunos surdos , da análise de concepções, do tema Sinais/Gestos seja nas diferentes línguas gestuais e a LIBRAS.

Esperamos obter uma avaliação sobre o processo de inclusão destes estudantes com necessidades especiais em um ambientes inclusivo de ensino, de forma que esses resultados sejam divulgados em revistas científicas e congressos, podendo servir como auxílio para outros profissionais que se interessem pelo tema achando-0 relevante para o processo ensino-aprendizagem.

Além da analise durante 0 ano letivo de 2014 , do crescimento do processo de aprendizagem, através de reuniões pedagógicas e conselhos de classe.

\section{Recursos necessários}

\begin{tabular}{l|l|l} 
O que vou precisar & Descrição & Como obter \\
\hline $\begin{array}{l}\text { Croma Key; Maquina de filmar, } \\
\text { computador. Programa adoble } \\
\text { premier 11, Hd externo de 1 TB, } \\
\text { tripés, focos ( lâmpadas, spots de } \\
\text { filagem) }\end{array}$ & $\begin{array}{l}\text { Material necessário para compor a Sala } \\
\text { de recurso, para o processo de filmagem } \\
\text { do dicionário on line, exigido pela ONG da } \\
\text { Suécia, responsável pelo site } \\
\text { WWW.spreadthesign.com }\end{array}$ & $\begin{array}{l}\text { Recursos obtidos via Edital Projetos } \\
\text { Inovadores, verba prevista para } \\
\text { material de consumo. }\end{array}$ \\
\hline
\end{tabular}

\section{Marketing e comunicação}

Trabalhar pela inclusão é o que vai mover a comunicação do projeto. A localização da escola em que estou gestora é privilegiada, no Centro Urbano, porém temos pelo Rio de Janeiro ESCOLAS NO INTERIOR SEM POSSIBILIDADE DE RECEBER INTÉRPRETE, não podendo atender assim, alunos surdos. Faltam também professores capacitados. Esta realidade é comum em todo Brasil. Este trabalhão não é para o IEPIC é para auxiliar e ajudar a comunicação e a vida acadêmica dos surdos do mundo. Para melhorar o ensinoaprendizagem e comunicação gestual dos surdos trazemos este projeto inovador no Brasil, o Dicionário on line SpreadtThesSing.com.

Infelizmente o surdo é considerado estrangeiro em seu próprio país. Situação que o conduz ao isolamento lingüístico e social. Enquanto os alunos ouvintes transportam os livros e seus dicionários para casa podendo ler e estudar a sua língua materna (português), os surdos na maioria das vezes, não tem acesso a estes materiais na sua língua materna (libra).

Os resultados deste projeto devem, além de contribuir para o ensino e aprendizagem da Ciência (por apresentar muitos conceitos sem significados gestuais), iniciar a divulgação de novos termos em Língua Gestual, deve também subsidiar discussões nas comunidades surdas e científicas sobre essa questão.

Vamos divulgar amplamente 0 acesso ao site por familiares, pelo INES (Instituto Nacional dos Surdos) e principalmente pelos professores como forma de facilitar em sala de aula a vida acadêmica dos alunos surdos. Através da SEEDUC, esperamos que após os primeiros resultados positivos comprovados estatisticamente, possam ampliar o material para as escolas estaduais do Rio de Janeiro, através dos NAPES e do CAS. 


\section{Organização e gerência do empreendimento}

\begin{tabular}{|c|c|c|c|}
\hline Nome & Função & Formação/ Experiência & Principais atividades (no Projeto) \\
\hline Renata & Diretora & $\begin{array}{l}\text { Desempenha a função de gestora } \\
\text { há mais de } 13 \text { anos, sendo } 3 \text { anos } \\
\text { nesta Unidade, com } 20 \text { anos de } \\
\text { magistério. Formação: Bacharel em } \\
\text { Direito, com Licenciatura para } \\
\text { Direito e Legislação no Ens. Médio. } \\
\text { Curso de Mediação escolar. MBA } \\
\text { Gestão Empreendedora em } \\
\text { Educação }\end{array}$ & $\begin{array}{l}\text { Gestora responsável pela tomada de } \\
\text { preços, orçamentos e prestação de } \\
\text { contas das verbas destinadas à escola. } \\
\text { Responsável pelo tramite burocrático } \\
\text { junto a SEEDUC, para a formalização do } \\
\text { convênio com a UFF e demais parcerias } \\
\text { do Projeto. }\end{array}$ \\
\hline Ruth Mariani & $\begin{array}{l}\text { Profa da Sala de } \\
\text { Recurso }\end{array}$ & $\begin{array}{l}\text { Profa de Ed. Física, atuando na } \text { escola com inclusão desde 1997, } \\
\text { sendo uma das pioneiras na } \\
\text { implantação das salas de Recursos. } \\
\text { Doutoranda pela UFF, e } \\
\text { responsável pelo atendimento de } 47 \\
\text { alunos especiais. }\end{array}$ & $\begin{array}{l}\text { Planejar, executar e controlar o projeto. } \\
\text { Buscar parcerias com entidades ligadas } \\
\text { ao projeto. } \\
\text { Responsável pela visita a outros países. } \\
\text { Reunir os professores, responsáveis } \\
\text { para divulgação do projeto com a equipe } \\
\text { escolar. } \\
\text { Fazer a analise junto com a Equipe } \\
\text { pedagógica dos resultados do projeto, } \\
\text { visando à aprendizagem dos alunos. }\end{array}$ \\
\hline Dilmar & $\begin{array}{l}\text { Coordenador } \\
\text { Pedagógico }\end{array}$ & $\begin{array}{l}\text { Prof. De Ciências, foi membro da } \\
\text { SEEDUC por aproximadamente } 7 \\
\text { anos, atuou com Orientador } \\
\text { Tecnológico da escola, sendo } \\
\text { responsável por todo laboratório de } \\
\text { informática e as revistas on line. } \\
\text { Está na função de Coordenador há } \\
2 \text { anos, por solicitação do corpo } \\
\text { docente e direção. }\end{array}$ & $\begin{array}{l}\text { Responsável pela observância das } \\
\text { adaptações curriculares necessárias } \\
\text { para os alunos especiais junto a Profa } \\
\text { da sala de recurso e o Napes. } \\
\text { Solicitar profissionais especializados } \\
\text { para capacitações necessárias para } \\
\text { atendimento dos alunos especiais. } \\
\text { Preparar a capacitação dos professores } \\
\text { e realizá-la durante os encontros } \\
\text { pedagógicos. } \\
\text { Analisar junto com o corpo docente os } \\
\text { resultados do projeto. }\end{array}$ \\
\hline
\end{tabular}

\section{Principais processos}

A tabela a seguir, mostra o perfil da equipe e os principais processos de trabalho necessários para a realização do empreendimento: 


\section{DICIONÁRIO ON LINE SPREAD THE SIGN digital para a educação: Integração internacional de um recurso para surdos}

\begin{tabular}{|c|c|c|}
\hline PROCESSOS DO SEU EMPREENDIMENTO & COLABORADOR & PERFIL NECESSÁRIO \\
\hline $\begin{array}{l}\text { Responsabilizar-se pelo ambiente multimídia; } \\
\text { realizar oficinas para alunos e professores para } \\
\text { explicar a utilização da Plataforma no site: } \\
\text { WWW.spreadthesign.com }\end{array}$ & Isabela & $\begin{array}{l}\text { Conhecimento: Professora concursada, atua no } \\
\text { Laboratório de informática e é responsável pelas } \\
\text { salas multimídias. } \\
\text { Habilidade: Boa comunicação verbal, possui } \\
\text { conhecimento tecnológico para ajudar no acesso da } \\
\text { plataforma. } \\
\text { Atitude: Domínio de classe, criatividade, } \\
\text { responsabilidade e ética profissional. }\end{array}$ \\
\hline $\begin{array}{l}\text { Utilizar ambiente da sala de recurso para } \\
\text { filmagem e edição de som dos vídeos do } \\
\text { dicionário on line. }\end{array}$ & Carlos André & $\begin{array}{l}\text { Conhecimento: Aluno do } 3^{\circ} \text { Ano do Curso Normal, } \\
\text { deficiente visual, presidente do grêmio estudantil e } \\
\text { responsável pela Rádio Escolar. Aluno } \\
\text { representante da escola no CONAE e luta pelos } \\
\text { direitos dos alunos com necessidades especiais. } \\
\text { Excelente aluno e dedicado a escola. } \\
\text { Habilidade: Possui curso de locução. Totalmente } \\
\text { tecnológico, gosta de inovação e de trabalhar com } \\
\text { edições de vídeos. } \\
\text { Atitude: O aluno possui uma liderança positiva na } \\
\text { escola, sendo respeitado e admirado por todos. Sua } \\
\text { deficiência visual, o torna um exemplo devido a sua } \\
\text { determinação. }\end{array}$ \\
\hline $\begin{array}{l}\text { Utilizar o ambiente da plataforma, como } \\
\text { mecanismo facilitador para } 0 \text { ensino- } \\
\text { aprendizagem dos alunos surdos. }\end{array}$ & $\begin{array}{l}\text { Equipe de professores } \\
\text { da U.E. }\end{array}$ & $\begin{array}{l}\text { Conhecimento: Professores concursados, } \\
\text { experientes, } 60 \% \text { dos nossos professores possuem } \\
\text { Pós Graduação, } 30 \% \text { Mestrado e } 10 \% \text { Doutorado, } \\
\text { são dedicados aos projetos desenvolvidos na } \\
\text { escola. } \\
\text { Habilidade: Gostam de inovação e de ensinar de } \\
\text { diferentes formas. } \\
\text { Atitude: apresenta um grande comprometimento } \\
\text { com a qualidade da educação e estão em } \\
\text { constantes capacitações e discussões sobre } \\
\text { políticas educacionais. }\end{array}$ \\
\hline $\begin{array}{l}\text { Confeccionar materiais para as reuniões de } \\
\text { divulgação do projeto e encaminhar os alunos } \\
\text { com necessidades especiais para avaliação do } \\
\text { NAPES e sala de recurso. }\end{array}$ & Sebastiana & $\begin{array}{l}\text { Conhecimento: Servidora de apoio, que após curso, } \\
\text { assumiu a função há } 8 \text { anos, realizou capacitação } \\
\text { pela escola SEEDUC. } \\
\text { Habilidade: Possui domínio no exercício de sua } \\
\text { função. } \\
\text { Atitude: Exerce com autonomia, responsabilidade e } \\
\text { conhecimento. }\end{array}$ \\
\hline $\begin{array}{l}\text { Garantir a limpeza e organização da sala e } \\
\text { manutenção dos equipamentos }\end{array}$ & Roberto & $\begin{array}{l}\text { Conhecimento: Funcionário contratado pela } \\
\text { empresa terceirizada e muito dedicado a escola e } \\
\text { aos alunos. } \\
\text { Habilidade: ser organizado, manter o espaço limpo } \\
\text { e cuidadoso com o material da sala de Recurso. } \\
\text { Limpar corretamente os materiais tecnológicos que } \\
\text { compõe a sala. } \\
\text { Atitude: Organizado, prestativo, se colocando } \\
\text { sempre a disposição da escola, }\end{array}$ \\
\hline
\end{tabular}

\begin{tabular}{|l|l|}
\hline Legenda: & Processo Pedagógico \\
\hline & Processo Administrativo \\
\hline & Processo de Apoio \\
\hline
\end{tabular}


Plano Financeiro Investimento (despesa de capital)

\begin{tabular}{|c|c|c|c|}
\hline \multicolumn{4}{|c|}{ Investimentos (despesas de capital) } \\
\hline Item & Ano1 & Ano2 & Ano3 \\
\hline Obras e infraestrutura & $2.500,00$ & 0,00 & 0,00 \\
\hline Obras & $1.500,00$ & & \\
\hline Instalações & $1.000,00$ & & \\
\hline Material permanente & $13.708,00$ & 0,00 & 0,00 \\
\hline Câmara de Filmar & 950,00 & & \\
\hline Tripés para cenário & 758,00 & & \\
\hline Computadores & $8.500,00$ & & \\
\hline Ar condicionado split & $2.400,00$ & & \\
\hline Web cam & 300,00 & & \\
\hline Focos - Luz contínua para vídeo & 800,00 & & \\
\hline Total & $16.208,00$ & 0,00 & 0,00 \\
\hline
\end{tabular}

\section{Detalhamento}

Câmara de filmar - Canon Legria HF-M52

Tripés para cenário- kit porta fundos "Manfrotto1314B

Computadores - Aquisição 5 computadores com placa de vídeo especial para a sala de recurso $\mathrm{R} \$$ $1.700,00,00$ (un)

Ar condicionado Split - Spinger Carrier 30.000BTUs c/ instalação

WEB CAM - Aquisição de 5 Web cam para a sala de recursos $\mathrm{R} \$ 60,000$ (Un)

Focos - Luz continua para vídeo- 1x Focos luz de día Walimex pro 600 com 5x24W lâmpadas, refletor, difusor e cabo corrente, $\mathrm{R} \$ 800,00$

Obras e instalações: A sala deverá ser realizada obras para Instalação de rede elétrica sustentável às maquinas e ao ar condicionado, e instalação dos computadores com cabeamento para a internet. 


\section{DICIONÁRIO ON LINE SPREAD THE SIGN digital para a educação: Integração internacional de um recurso para surdos}

\section{Despesas correntes}

\begin{tabular}{|c|c|c|c|}
\hline \multicolumn{4}{|c|}{ Projeção das Despesas Correntes } \\
\hline Material de Consumo & Total ANO 1 & Total ANO 2 & Total ANO 3 \\
\hline Lâmpada de reposição & 200 & 200 & 200 \\
\hline Hd externo & 315 & 315 & 315 \\
\hline Cenário & 422,4 & 0 & 0 \\
\hline Pen drive & 279,9 & 0 & 279,9 \\
\hline Papel Ofício & 1150 & 1150 & 1150 \\
\hline Toner & 250 & 250 & 250 \\
\hline Impressora hp Muntifuncional & 459 & 0 & 0 \\
\hline Total & 3076,3 & 1915 & 2194,9 \\
\hline Passagens e Locomoção & Total ANO 1 & Total ANO 2 & Total ANO 3 \\
\hline $\begin{array}{l}\text { Inscrição, transporte, alimentação e acomodação } \\
\text { para congressos para a divulgação do dicionário }\end{array}$ & & & \\
\hline & 2000 & 2400 & 2400 \\
\hline Total & 2000 & 2400 & 2400 \\
\hline Serviços de Terceiros & Total ANO 1 & Total ANO 2 & Total ANO 3 \\
\hline Manutenção dos equipamentos & 400 & 400 & 400 \\
\hline Total & 400 & 400 & 400 \\
\hline Total das Despesas Correntes & 5476,3 & 4715 & 4994,9 \\
\hline
\end{tabular}

\section{Detalhamento}

Lâmpada de reposição - reposição para equipamento de iluminação das filmagens

HD Externo - para maior armazenamento e segurança das atividades e filmagens

CENÁRIO - Cenário Kentucky (3m x 3,5 m)

Pen drive - 1 por disciplinas, 10 disciplinas, $\mathrm{R} \$ 27,99$ (Un), para planejamento de atividades a serem realizadas com alunos.

Papel Ofício - 10 resmas por mês

Toner_ Complemento para utilização da impressora

Impressora hp Muntifuncional - Facilitar a impressão das atividades realizadas de forma independente e menos burocrática 


\section{Despesas administrativas e de pessoal}

*valor utilizado como contrapartida

\begin{tabular}{|l|l|l|l|}
\hline \multicolumn{4}{|l}{ Projeção das Despesas Administrativas e de Pessoal } \\
\hline Administrativas & Total ANO 1 & Total ANO 2 & Total ANO 3 \\
\hline Energia elétrica & 3500 & 3284 & 3856,52 \\
\hline Marketing & 800 & 750 & 750 \\
\hline Total & 4300 & 4034 & 4606,52 \\
\hline Pessoal & Total ANO 1 & Total ANO 2 & Total ANO 3 \\
\hline Diretora & 200 & 200 & 200 \\
\hline Diretora Adjunta & 350 & 456,52 & 456,52 \\
\hline Coordenadora Pedagógica & 1985,2 & 1980 & 1700 \\
\hline Profissional de Sala de Recursos & 8954,23 & 8954,23 & 8954,23 \\
\hline Total & 11489,43 & 11590,75 & 11310,75 \\
\hline Total das Despesas Correntes & 15789,43 & 15624,75 & 15917,27 \\
\hline
\end{tabular}

\section{Necessidade de recursos}

\begin{tabular}{|c|c|c|c|c|}
\hline \multicolumn{4}{|l|}{ Cálculo da Necessidade de Recursos } & \multirow[b]{2}{*}{ TOTAL } \\
\hline Item & ANO 1 & ANO 2 & ANO 3 & \\
\hline I. Total das Despesas Correntes & $5.476,30$ & $4.715,00$ & $4.994,90$ & $15.186,20$ \\
\hline Material de Consumo & $3.076,30$ & $1.915,00$ & $2.194,90$ & $7.186,20$ \\
\hline Passagens e Despesas com Locomoção & $2.000,00$ & $2.400,00$ & $2.400,00$ & $6.800,00$ \\
\hline Ss serviços de Terceiros & 400,00 & 400,00 & 400,00 & $1.200,00$ \\
\hline II. Total de Despesas Administrativas & $4.300,00$ & $4.034,00$ & $4.606,52$ & $12.940,52$ \\
\hline III. Total de Despesas com Pessoal & $11.489,43$ & $11.590,75$ & $11.310,75$ & $34.390,93$ \\
\hline IV. Total de Despesas de Capital (investimentos) & $16.208,00$ & 0,00 & 0,00 & $16.208,00$ \\
\hline Necessidade de Recursos (I+||+||I+|V) & $37.473,73$ & $20.339,75$ & $20.912,17$ & $78.725,65$ \\
\hline Recursos Edital & $21.684,30$ & $4.715,00$ & $4.994,90$ & $31.394,20$ \\
\hline Recursos da Organização (contrapartida) & $15.789,43$ & $15.624,75$ & $15.917,27$ & $47.331,45$ \\
\hline
\end{tabular}




\section{DICIONÁRIO ON LINE SPREAD THE SIGN digital para a educação: Integração internacional de um recurso para surdos}

\begin{tabular}{|l|l|l|l|l|}
\hline \multicolumn{5}{|c|}{ Cálculo da Necessidade de Recursos } \\
\hline Item & ANO 1 & ANO 2 & ANO 3 & TOTAL \\
\hline I. Total das Despesas Correntes & 5476,30 & 4715,00 & 4994,90 & 15186,20 \\
\hline Material de Consumo & 3076,30 & 1915,00 & 2194,90 & 7186,20 \\
\hline Passagens e Despesas com Locomoção & 2000,00 & 2400,00 & 2400,00 & 6800,00 \\
\hline Serviços de Terceiros & 400,00 & 400,00 & 400,00 & 1200,00 \\
\hline II. Total de Despesas Administrativas & 4300,00 & 4034,00 & 4606,52 & 12940,52 \\
\hline III. Total de Despesas com Pessoal & 11489,43 & 11590,75 & 11310,75 & 34390,93 \\
\hline IV. Total de Despesas de Capital (investimentos) & 16208,00 & 0,00 & 0,00 & 16208,00 \\
\hline Necessidade Total de Recursos (I+II+III+IV) & 37473,73 & 20339,75 & 20912,17 & 78725,65 \\
\hline Recursos Edital + Recursos da Organização & 37473,73 & 20339,75 & 20912,17 & 78725,65 \\
\hline Recursos Edital & 21684,30 & 4715,00 & 4994,90 & 31394,20 \\
\hline Recursos da Organização (contrapartida) & 15789,43 & 15624,75 & 15917,27 & 47331,45 \\
\hline
\end{tabular}

\section{Validações}

\begin{tabular}{|c|l|l|l|}
\hline Itens Financiáveis & $\begin{array}{l}\text { Valores } \\
\text { Consolidados }\end{array}$ & $\%$ & Validação \\
\hline Despesas Correntes & $\begin{array}{l}15.697,10 \\
15.697,10\end{array}$ & $\begin{array}{l}50 \% \\
50 \%\end{array}$ & ok: $=50 \%$ \\
Despesas de Capital (máximo de $50 \%$ do projeto) & $31.394,20$ & $100 \%$ & ok: <90 mil \\
\hline Total de Recursos Solicitados & & & \\
\hline
\end{tabular}




\begin{tabular}{|l|l|}
\hline Contrapartida & $47.331,45$ \\
\hline Valor total da contrapartida & $31.394,20$ \\
\hline Valor solicitado ao edital pelo projeto & \\
\hline $\begin{array}{l}\text { Percentual: contrapartida } \\
\text { recurso solicitado }\end{array}$ & $60 \%$ \\
\hline Contrapartida & $40 \%$ \\
\hline $\begin{array}{l}\mid \\
\text { Valor total da contrapartida } \\
\text { Valor solicitado ao edital pelo projeto }\end{array}$ \\
\hline $\begin{array}{l}\text { Percentual: contrapartida } \\
\text { recurso solicitado }\end{array}$ & $47.331,45$ \\
\hline
\end{tabular}

